\title{
Elucidating the Reactivity of Tris(trimethylsilyl)phosphite and Tris(trimethylsilyl)phosphate Additives in Carbonate Electrolytes-A Comparative Online Electrochemical Mass Spectrometry Study
}

\author{
Aurélie Guéguen, ${ }^{\dagger, \S}$ Christoph Bolli, ${ }^{*},{ }^{\dagger} \S_{\odot}$ Manuel A. Mendez, ${ }^{\dagger}$ and Erik J. Berg, ${ }^{\dagger,}$ \\ ${ }^{\dagger}$ Electrochemistry Laboratory, Paul Scherrer Institute, 5232 Villigen, Switzerland \\ ${ }^{\ddagger}$ BASF SE, GCN/EE - M311, 67056 Ludwigshafen, Germany
}

Supporting Information

\begin{abstract}
The electrolyte additives tris(trimethylsilyl)phosphite (TMPSi) and tris(trimethylsilyl)phosphate (TMSPa) have shown their potential to improve lifetime and decrease impedance build-up in lithium ion batteries (LIBs) in several studies. Online electrochemical mass spectrometry (OEMS) was applied to study the effect of TMSPi and TMSPa on a gas releasing parasitic reaction during cycling of HE-NCM/ graphite cells in different electrolytes to elucidate their working mechanisms, for which so far contradictive claims can be found in the literature. The results underline the chemical instability of the two additives in solution and show that they have, with one exception, little or no effect on the release of $\mathrm{O}_{2}$ and $\mathrm{CO}_{2}$ which would be expected in the case of a passivating surface layer suppressing electrolyte decomposition. The decreased $\mathrm{POF}_{3}$ evolution and the formation of $\mathrm{Me}_{3} \mathrm{SiF}$ indicates that the main role of both additives is that of a chemical scavenger, e.g., for HF, which leads to decreased acidification of the electrolyte and thus a longer lifetime of LIBs containing these electrolytes.
\end{abstract}

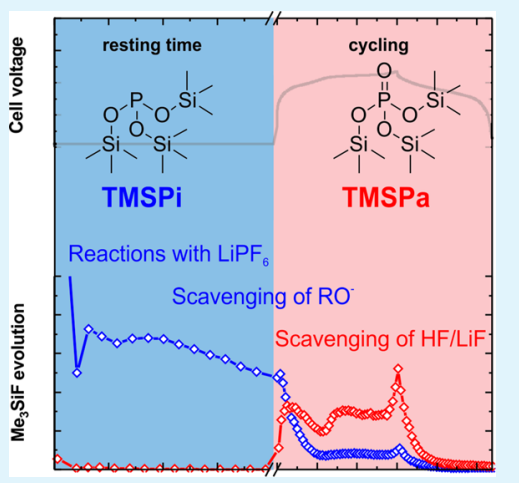

KEYWORDS: Li-ion batteries, Li-rich NCM, electrolyte additives, online electrochemical mass spectrometry, fluoroethylene carbonate

\section{INTRODUCTION}

No ideal electrolyte is existing that exhibits all characteristics required for seamless operation of Li-ion batteries (e.g., high $\mathrm{Li}^{+}$conductivity, low viscosity, electrochemically stable in an electrode operating voltage window, chemical inertness toward all cell components, etc.). Modern commercial Li-ion electrolytes are mainly based on $\mathrm{LiPF}_{6}$ salt dissolved in a mixture of cyclic (e.g., ethylene carbonate EC) and linear (e.g., dimethyl carbonate (DMC) or diethyl carbonate (DEC)) carbonate solvents. The success of these carbonate electrolytes relies largely on their wide thermodynamic electrochemical stability window $\left(\sim 1.3-4.5 \mathrm{~V} \text { vs } \mathrm{Li} / \mathrm{Li}^{+}\right)^{1}$ and their ability to form a protective and stable solid electrolyte interphase (SEI) on the negative graphite electrode in the first cycle of the $\mathrm{Li}$-ion cell. However, side reactions are yet prevalent, particularly at the positive transition metal oxide electrode operating at high potentials $(>4.3 \mathrm{~V})$, leading to loss of active lithium along with cell impedance growth, both of which belong to the main causes for a declining cell performance and shortened lifetime.

Electrolyte additives have been proven to prolong the lifetime of the Li-ion cell, and several additives with varying functionalities can be found in modern cells. For instance, molecular redox shuttles can be used to improve cell safety in the case of cell overcharge, ${ }^{2,3}$ additives such as vinylene carbonate (VC) or fluoroethylene carbonate (FEC) are selected due to their ability to form improved SEIs, ${ }^{4}$ and further additives of interest are scavengers of undesired electrolyte species such as HF. ${ }^{5}$ Detailed information on the exhaustive number of investigated compounds is found in recent review papers. ${ }^{2,3}$

Two of the most widely investigated additives are tris(trimethylsilyl)phosphate and tris(trimethylsilyl)phosphite (hereafter denoted TMSPa and TMSPi, respectively), differing solely with respect to the oxidation state of the central phosphorus atom (Figure 1). TMSPi was introduced as an electrolyte additive for Li-ion batteries in a patent from Samsung Ltd. in $2009^{6}$ and since then has been intensively investigated and shown to improve the electrochemical performance of $\mathrm{Li}$-ion cells based on various electrode
TMSPi<smiles>C[Si](C)(C)OP(O[Si](C)(C)C)O[Si](C)(C)C</smiles><smiles>C[Si](C)(C)OP(=O)(O[Si](C)(C)C)O[Si](C)(C)C</smiles>

TMSPa
Tristrimethylsilyl phosphite Tristrimethylsilyl phosphate

Figure 1. Chemical structures of TMSPi and TMSPa.

Received: August 7, 2019

Accepted: November 27, 2019

Published: November 27, 2019 
materials. $^{7-12}$ Dahn et al. made in 2014 a first systematic comparison of the performances of TMSPi and TMSPa as electrolyte additives (in blends with other additives) and found that cells with TMSPa only slightly improved the performance compared to cells with blank electrolyte solution. ${ }^{8,13}$ In contrast, cells with TMSPi showed significantly improved charge end point slippage and Coulombic efficiency which they attribute to slower rate of parasitic reactions in the presence of the additive. ${ }^{8}$ Despite these latter findings, several further reports (with sometimes contradictory claims) have emerged showing significantly enhanced cycling performance of cells rather than including TMSPa. ${ }^{14-17}$

The disparate results on the beneficial role of TMSPi and TMSPa (collectively hereafter abbreviated TMSPx) can largely be explained by the lack of fundamental understanding of how these electrolyte additives operate. The most frequently discussed mechanism is the formation of a protective surface layer on the cathode active material (CAM) for TMSPa ${ }^{15-19}$ and TMSPi ${ }^{7,9,11,20-22}$ due to oxidation of the additive at lower potentials than the conventional carbonate electrolytes. However, the various experimental and theoretical studies make contradictive claims about the oxidative stability of the additives, ${ }^{715,23,24}$ and thus it is still unclear if and under which conditions these additives are oxidized in the electrolyte. Recent studies propose that TMSPi or chemical decomposition products of it coordinate to the surface of the CAM to prevent side reactions and stabilize the material. ${ }^{23,25,26}$ As further modi operandi scavenging and/or stabilization of several potentially detrimental compounds were suggested: The most commonly proposed is HF scavenging by the $-\mathrm{SiMe}_{3}$ moieties of TMSPi ${ }^{9-11,22}$ and TMSPa. Furthermore, oxygen scavenging by oxidation of the $\mathrm{P}$ (III) atom in TMSPi to a $\mathrm{P}(\mathrm{V})$ as proposed for triethyl phosphite, ${ }^{27}$ stabilization of $\mathrm{POF}_{3}$ by the free-electron pair in TMSPi, and subsequent suppression of $\mathrm{LiPF}_{6}$ hydrolysis ${ }^{11}$ as well as scavenging of alkoxides by TMSPi and thus preventing EC decomposition ${ }^{28}$ were proposed.

Regardless of the operating mechanisms, the addition of TMSPx to the electrolyte is expected to reduce the extent of side reactions. Several side products of these electrolyte decomposition reactions are volatile, and a more mechanistic understanding of their formation can be obtained by monitoring their evolution during cycling. Online electrochemical mass spectrometry (OEMS) was shown by us (and others) to provide unparalleled means to monitor such reactions by following the gas evolution inside the Li-ion cell during operation. Both chemical and electrochemical side reactions, involving the active materials and/or the electrolyte, are readily discernible with unrivaled sensitivity. For instance, Li-ion oxide cathode surface instabilities may lead to the release of $\mathrm{O}_{2},{ }^{29}$ and electrolyte solvent decomposition typically causes $\mathrm{CO}_{2}, \mathrm{C}_{2} \mathrm{H}_{4}$, and $\mathrm{H}_{2}$ to evolve while the degradation of the $\mathrm{LiPF}_{6}$ salt generally generates $\mathrm{POF}_{3}{ }^{30,31}$ In a recently published study we could already show that the application of TMSPa as electrolyte additive leads also to the formation of $\mathrm{Me}_{3} \mathrm{SiF}$. With the help of this gas we were able to assign the main role of TMSPa in a FEC/DEC based electrolyte to be the one of a chemical scavenger for both $\mathrm{HF}$ and $\mathrm{LiF}^{32}$ Furthermore, the potential dependent evolution of $\mathrm{Me}_{3} \mathrm{SiF}$ proved valuable to monitor the operando formation of $\mathrm{F}^{-}$in LIBs.

The aim of the present study is to apply the knowledge from our previous study and evaluate (1) the differences between
TMSPi and TMSPa and (2) the differences between EC and FEC based electrolyte systems in advanced Li-ion full cells based on state-of-the-art electrodes (graphite vs overlithiated layered mixed transition metal oxide $\mathrm{Li}_{x+1} \mathrm{Ni}_{y} \mathrm{Co}_{z} \mathrm{Mn}_{1-y-z} \mathrm{O}_{2}$, denoted HE-NCM vs Graphite) and electrolyte ( $1 \mathrm{M} \mathrm{LiPF}_{6}$ in 12:88 (F)EC:DEC). We primarily target the question of whether these additives and the surface layers they form are effectively preventing reactions at the electrolyte/cathode interface (leading to reduced gas formation), if they suppress as surface complexing agents or $\mathrm{O}_{2}$ scavengers the release from oxygen from the CAM or if they act as $\mathrm{LiPF}_{6}$ electrolyte salt stabilizers which would lead to less $\mathrm{POF}_{3}$ evolution, and aim to answer these questions by operando monitoring of the gas evolution with OEMS.

\section{EXPERIMENTAL SECTION}

II.1. Electrode Preparation. The positive electrodes consist of 89 wt \% HE-NCM (BASF SE), 5 wt \% polyvinylidene fluoride (PVDF Solef 5130, Solvay), 4.64 wt \% Super C65 carbon (Imerys Graphite \& Carbon, Switzerland), and 1.36 wt \% graphite SFG6L coated on Celgard 2400 monolayer polypropylene. The active material loading was in the range $14.1 \mathrm{mg} / \mathrm{cm}^{2}$. Graphite electrodes consisted of 95.7 wt \% SFG6 (Imerys Graphite \& Carbon, Switzerland), 0.5\% Super C65 Carbon, and 3.8 wt \% carboxymethyl cellulose (CMC) coated on $\mathrm{Cu}$ foil. Detailed information about the electrode preparation of HE$\mathrm{NCM}$ and graphite electrodes can be obtained from previous publications. $^{32}$

II.2. Electrochemical Measurements. All cells were assembled in a glovebox filled with argon. HE-NCM $\left(\mathrm{Li}_{1.17}\left(\mathrm{Ni}_{0.22} \mathrm{Co}_{0.12} \mathrm{Mn}_{0.66}\right)_{0.83} \mathrm{O}_{2}\right)$ electrodes were cycled vs SFG6 counter electrodes. All electrochemical measurements were carried out in electrolytes $\left[1 \mathrm{M} \mathrm{LiPF}_{6}, 12: 88(\mathrm{w} / \mathrm{w})\right.$ of ethylene carbonate (EC) and diethyl carbonate (DEC) (battery grade solvents, BASF $\mathrm{SE})$ or $\left(1 \mathrm{M} \mathrm{LiPF}_{6}, 12: 88(\mathrm{w} / \mathrm{w})\right.$ of fluoroethylene carbonate (FEC) and diethyl carbonate (DEC) (battery grade, BASF SE)]. Tris(trimethylsilyl)phosphate (TMSPa, Sigma-Aldrich, >98\%) and tris(trimethylsilyl)phosphite (TMSPi, Alfa Aesar, 96\%) were used as received. If not mentioned otherwise, 1 wt \% of TMSPa or 1 wt \% TMSPi was added to the reference electrolytes to prepare electrolytes with an additive concentration $\sim 40 \mathrm{mmol} / \mathrm{L}$. The amount of trace water in the electrolytes, determined using Karl Fischer titration, was $<30 \mathrm{ppm}$. The additives were added to the blank electrolytes just before assembling the OEMS cells so that the electrolytes were as fresh as possible. The assembled HE-NCM/graphite cells were equilibrated at a constant voltage of $0.2 \mathrm{~V}$ (open circuit potential value) for $4 \mathrm{~h}$ prior to electrochemical cycling. Galvanostatic cycling

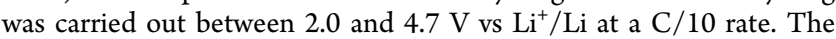
specific charges (not reported on the figures) were found similar to those reported previously $(\sim 300 \mathrm{mAh} / \mathrm{g}$ and $250 \mathrm{mAh} / \mathrm{g}$ at the end of the first charge and discharge, respectively). ${ }^{33}$ All measurements were carried out at room temperature.

II.3. Online Electrochemical Mass Spectrometry (OEMS). The OEMS setup was described elsewhere ${ }^{34}$ and operates with a quadrupole mass spectrometer (QMS 200, Pfeiffer) for partial pressure measurements, a pressure transducer (PAA-33X, Keller Druck AG) for total cell pressure, temperature, and internal volume determination, stainless steel gas pipes, Swagelok fittings $(3 \mathrm{~mm}$ compression tube fittings, Swagelok, OH, U.S.A.) to connect the OEMS cell, a set of solenoid valves (2-way magnetic valve, Series 99, silver-plated nickel seal, Parker), and a scroll pump (nXDS15i, EDWARDS $\mathrm{GmbH}$ ) for efficient flushing. The magnetic valves are electronically controlled with a Solid State Relay Module (NI 9485 measurement System, National Instruments) and connected to a computer with a LabView Software (NI Labview 2013, National Instruments). For partial pressure and gas evolution rate analysis, 1.3 $\mathrm{mL}$ of gas are extracted from the headspace $(\sim 4 \mathrm{~mL})$ of the cell and replaced by pure $\operatorname{Ar}$ (quality 5.0). Calibration gas bottles were utilized to relate the MS ion-current signals at $m / z=2,26,32$, and 44 to 

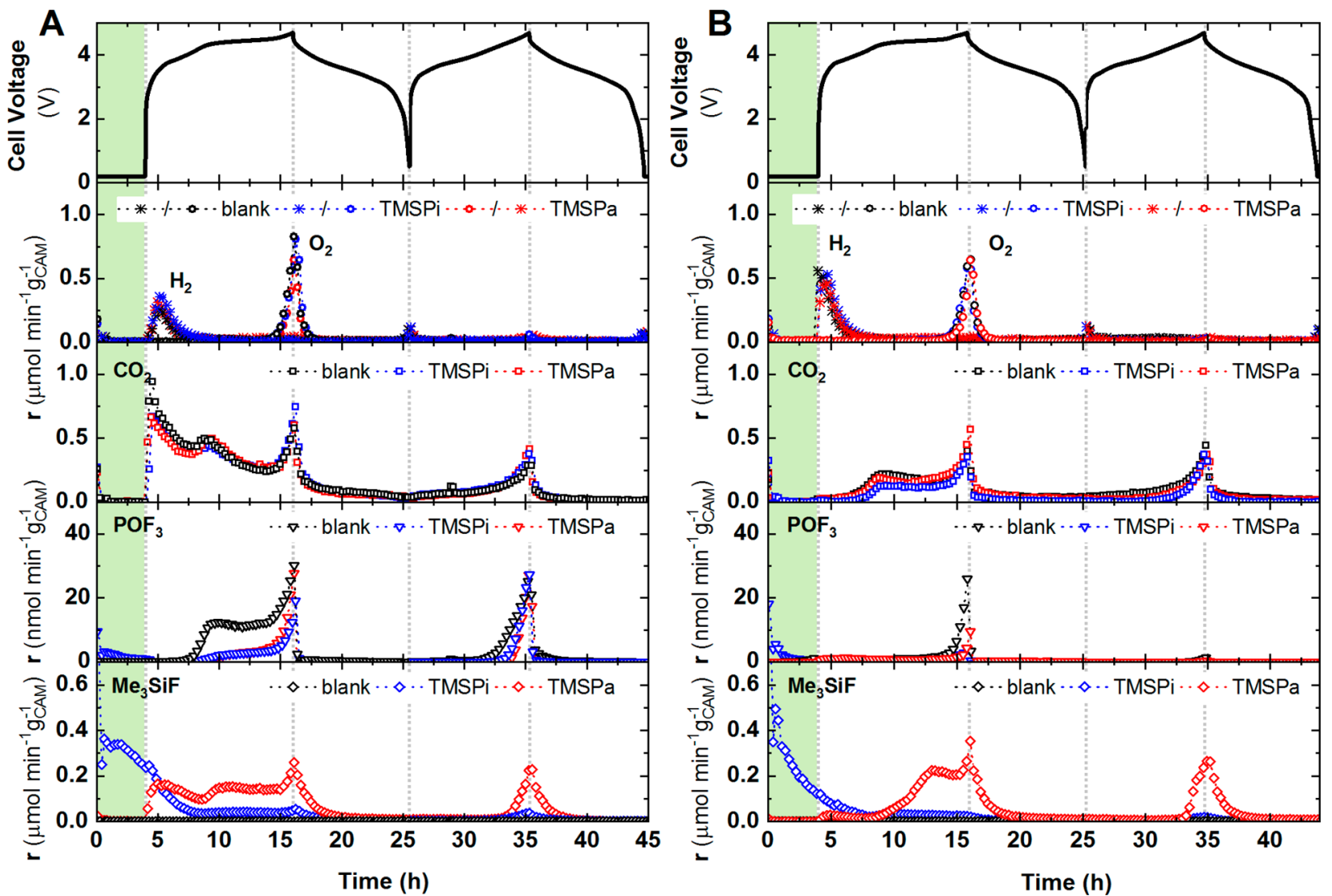

Figure 2. Gas evolution rates of $\mathrm{O}_{2}, \mathrm{H}_{2}, \mathrm{CO}_{2}, \mathrm{POF}_{3}(m / z=85)$, and $\mathrm{Me}_{3} \mathrm{SiF}(m / z=77)$ for the two first galvanostatic cycles for HE-NCM electrodes cycled vs graphite between 0.5 and $4.7 \mathrm{~V}(\mathrm{C} / 10)$ in FEC:DEC (A) or EC/DEC (B) (12:88, $\left.1 \mathrm{M} \mathrm{LiPF}_{6}\right)$ based electrolyte containing no additive (blank, black), $1 \mathrm{wt} \%$ TMSPi (blue), or $1 \mathrm{wt} \%$ TMSPa (red). The $4 \mathrm{~h}$ resting period before cycling is highlighted in light green.

known concentrations of $\mathrm{H}_{2}, \mathrm{C}_{2} \mathrm{H}_{4}, \mathrm{O}_{2}$, and $\mathrm{CO}_{2}(1000 \mathrm{ppm}$ in $\mathrm{Ar})$, before and after the measurement. $\mathrm{POF}_{3}(\mathrm{~m} / z=85)$ and $\mathrm{Me}_{3} \mathrm{SiF}(\mathrm{m} /$ $z=77)$ were calibrated using a procedure described in a previous study. ${ }^{32}$ Please note that due the $m / z$ ratio of the $\mathrm{Me}_{3} \mathrm{SiF}$ fragment as well as its isotopic pattern can be assigned to the $\mathrm{Me}_{2} \mathrm{SiF}^{+}$fragment which therefore rules out that the observed peaks (especially during the resting period) are stemming from evaporation of the TMSPi additive.

All gas evolution rates and gas amounts are normalized with respect to the mass of the cathode active material (CAM).

\section{RESULTS}

For studying the gas evolution with OEMS three HENCM/ graphite cells were cycled in (F)EC/DEC electrolyte (12:88, 1 $\mathrm{M} \mathrm{LiPF}$ ) without additive (blank) or with either $1 \mathrm{wt} \%$ TMSPa or TMSPi, respectively. Figure $2 \mathrm{~A}$ shows representative curves for the $\mathrm{H}_{2}, \mathrm{CO}_{2}, \mathrm{O}_{2}, \mathrm{POF}_{3}$, and $\mathrm{Me}_{3} \mathrm{SiF}$ evolution for the three FEC containing electrolytes and Figure $2 \mathrm{~B}$ the same gas evolutions for the respective cells with electrolyte consisting of EC. The observed gas evolution can be divided in two parts: (1) Initial potential hold period for $4 \mathrm{~h}$ when cell stability is monitored and gas formation is assumed to result solely from chemical reactions and (2) the galvanostatic cycling period when the observed gas formation is the result of electrochemical and chemical reactions. These two parts will be discussed separately in the following section.

III.1. Gas Evolution during the Initial Resting Period. The cells are kept at a constant potential of $0.2 \mathrm{~V}$ for $4 \mathrm{~h}$ before being cycled in order not only to ensure proper wetting but also to obtain a stable baseline for the gas evolution. Typically, after attaching the cells to the OEMS setup, minor contaminations of atmospheric gases $\left(\mathrm{N}_{2}, \mathrm{O}_{2}\right.$, and $\left.\mathrm{CO}_{2}\right)$ are observed, which drop rapidly to zero. However, for TMSPi containing electrolytes a different behavior is observed for $\mathrm{POF}_{3}$ and $\mathrm{Me}_{3} \mathrm{SiF}$. For these two gases a continuous gas formation with an overall decreasing evolution rate takes place over the initial $4 \mathrm{~h}$ of the resting period. The integration of the gas evolution rates yields the released gas amounts, which are shown in Figure 3 (FEC based electrolytes) and Figure 4 (EC based electrolytes). With TMSPi present in the electrolyte, the amount of $\mathrm{POF}_{3}$ is $0.5 \pm 0.2 \mu \mathrm{mol} \mathrm{g}{ }^{-1}$ in the FEC and the EC containing ones. For the blank or TMSPa containing electrolytes no $\mathrm{POF}_{3}$ evolution during the initial $4 \mathrm{~h}$ is observed. It is important to note here that $\mathrm{POF}_{3}$ detected by OEMS can be both $\mathrm{POF}_{3}$ and $\mathrm{PF}_{5}$, the latter reacting to $\mathrm{POF}_{3}$ on the way from the cell to the MS. ${ }^{35}$ The amount of $\mathrm{Me}_{3} \mathrm{SiF}$ is $58 \pm 21 \mu \mathrm{mol} \mathrm{g}^{-1}$ in the FEC based electrolyte and $65 \pm 10$ $\mu \mathrm{mol} \mathrm{g}^{-1}$ for the electrolyte containing EC. The amount of $\mathrm{Me}_{3} \mathrm{SiF}$ evolution in the initial resting period is therefore not significantly affected by the type of cyclic carbonate used in the electrolyte formulation. The TMSPi containing electrolytes produce more than 80 times more $\mathrm{Me}_{3} \mathrm{SiF}$ than for the TMSPa containing ones, which have almost no gas evolution $(0.7 \pm 0.3$ $\mu \mathrm{mol} \mathrm{g}^{-1}$ (FEC); $0.4 \pm 0.1 \mu \mathrm{mol} \mathrm{g}^{-1}$ (EC)).

In another series of experiments, the rate of gas release of differently aged LP47 (3:7 EC/DEC, $1 \mathrm{M} \mathrm{LiPF}_{6}$ ) electrolytes containing 1 wt $\%$ of either TMSPa or TMSPi was studied. The $\mathrm{Me}_{3} \mathrm{SiF}$ evolution recorded during the resting period shows that only the 4 day aged electrolyte containing TMSPa has significant $\mathrm{Me}_{3} \mathrm{SiF}$ evolution whereas for TMSPi there was 

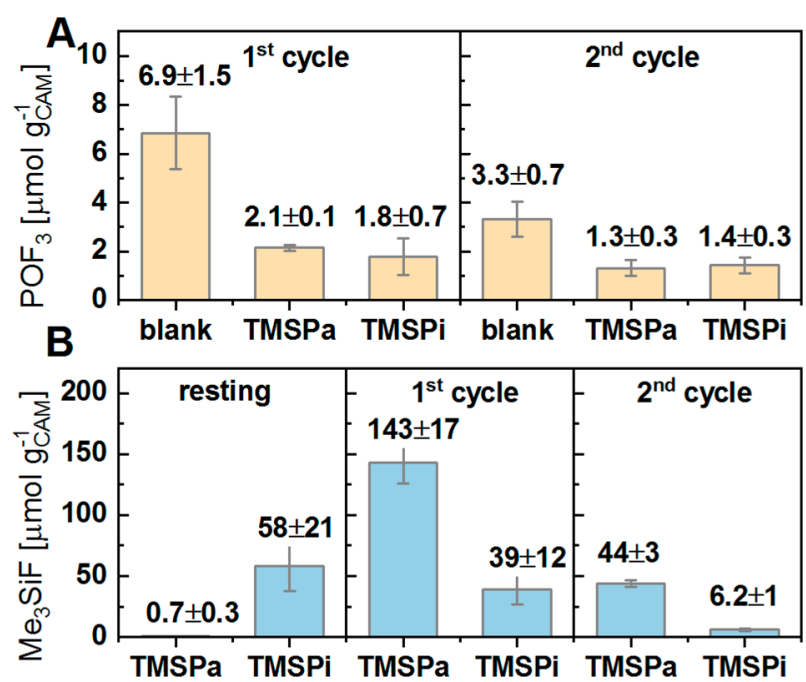

Figure 3. Gas amounts for $\mathrm{POF}_{3}(\mathrm{~A})$ and $\mathrm{Me}_{3} \mathrm{SiF}$ (B) from $\mathrm{FEC} /$ $\operatorname{DEC}(12: 88,1 \mathrm{M} \mathrm{LiPF} 6)$ based electrolytes for the first two galvanostatic cycles. All values and error bars are obtained from three cells.

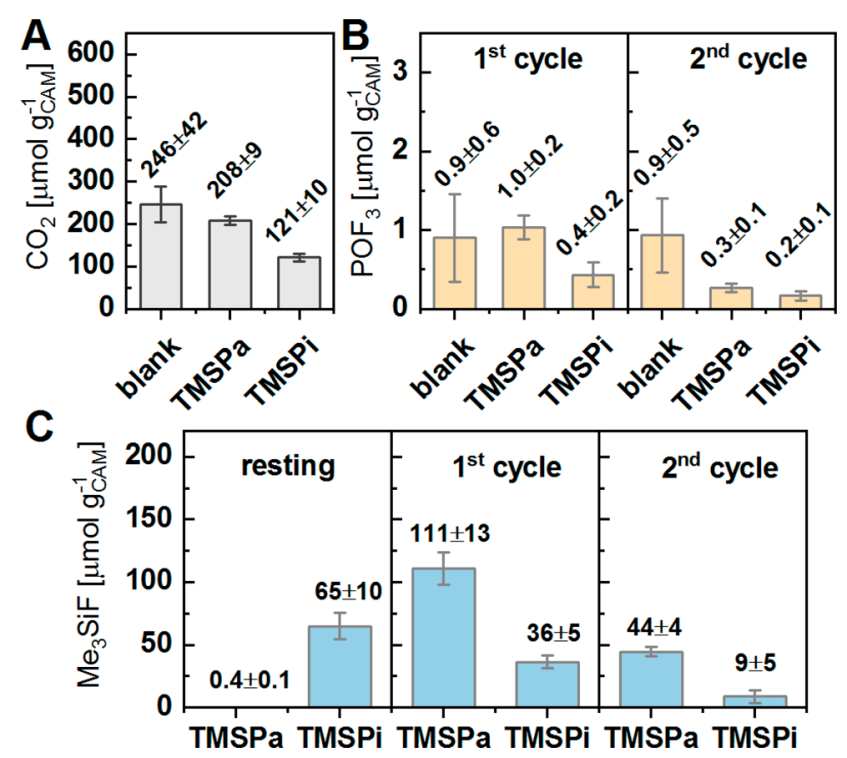

Figure 4. Gas amounts for $\mathrm{CO}_{2}(\mathrm{~A}), \mathrm{POF}_{3}(\mathrm{~B})$, and $\mathrm{Me}_{3} \mathrm{SiF}$ (C) from EC/DEC (12:88, $\left.1 \mathrm{M} \mathrm{LiPF}_{6}\right)$ based electrolytes for the first two galvanostatic cycles. All values and error bars are obtained from three cells.

a strong evolution only after 2 days and already much less gas evolution after 4 days (Figure S1). Clearly, the addition of TMSPi to the blank electrolytes leads to an immediate chemical reaction, most likely between the additive and the $\mathrm{LiPF}_{6}$ as was shown by $\mathrm{Qi}$ et al. ${ }^{36}$ In conclusion, there is a quite significant difference in the reactivity toward the electrolyte between the TMSPi additive containing a $\mathrm{P}(\mathrm{III})$ atom and TMSPa with a $\mathrm{P}(\mathrm{V})$.

III.2. Gas Evolution during Cycling: FEC/DEC Electrolyte. The underlying mechanisms for the evolution of $\mathrm{H}_{2}$, $\mathrm{CO}_{2}$, and $\mathrm{O}_{2}$ in electrolyte formulations with $\mathrm{FEC}$ as cyclic carbonate are already discussed in detail in our previous works $^{31,32}$ and thus are only summarized briefly here. $\mathrm{O}_{2}$ evolution onsets at low rates at a cell voltage of about $4.2 \mathrm{~V}$ and undergoes a strong exponential increase above $4.5-4.6 \mathrm{~V}$, as a result of the formation of a reconstructed O-deficient surface layer on the NCM oxide. ${ }^{37}$ The subsequent cycle shows only minor release of oxygen. $\mathrm{H}_{2}$ evolution is mainly observed at the beginning of the first charge, predominantly due to the reduction of FEC and solvent impurities such as moisture or glycols. ${ }^{38}$ A second peak is observed close to the cutoff potential, when oxidatively formed protic species (e.g., $\mathrm{HF}$ ) are subsequently reduced at the anode. The $\mathrm{CO}_{2}$ evolution shows three features in the first charge: First a strong evolution due to the FEC reduction during the SEI formation, ${ }^{39,40}$ second a maximum which was recently assigned to $\mathrm{Li}_{2} \mathrm{CO}_{3}$ oxidation ${ }^{37}$ or dissolution due to proton formation, and third an exponential increase close to the cutoff voltage because of electrolyte decomposition triggered by the evolving singlet oxygen ${ }^{41}$ as well as further $\mathrm{CO}_{2}$ release from surface carbonates. ${ }^{42}$ For the subsequent cycle only the latter evolution is observed at an onset potential of about 4.2-4.4 V. The gas evolution profiles for $\mathrm{O}_{2}, \mathrm{CO}_{2}$, and $\mathrm{H}_{2}$ in Figure 2 show no qualitative differences between the blank reference electrolyte and electrolyte containing 1 wt \% TMSPa, which was already observed in our previous study. ${ }^{32}$ Replacing TMSPa by TMSPi has also no significant influence on the evolution of $\mathrm{O}_{2}, \mathrm{CO}_{2}$, and $\mathrm{H}_{2}$.

In contrast, the gases $\mathrm{POF}_{3}$ and $\mathrm{Me}_{3} \mathrm{SiF}$ are strongly affected by the presence of the additives in the electrolyte. We recently demonstrated the main role of TMSPa in its chemical reactivity toward fluorides, such as $\mathrm{HF}$

$$
\mathrm{OP}\left(\mathrm{OSiMe}_{3}\right)_{3}+\mathrm{HF} \rightarrow \mathrm{OP}(\mathrm{OH})\left(\mathrm{OSiMe}_{3}\right)_{2}+\mathrm{Me}_{3} \mathrm{SiF}
$$

which in turn suppresses electrolyte acidification and $\mathrm{POF}_{3} /$ $\mathrm{PF}_{5}$ formation. ${ }^{32}$ Qualitative comparison of the $\mathrm{POF}_{3}$ evolution rate in Figure $2 \mathrm{~A}$ shows that the formation of $\mathrm{POF}_{3}$ is being affected by the presence of both additives in a similar fashion by strongly suppressing its formation at high voltages. Plotting the $\mathrm{POF}_{3}$ evolution rate as a function of the cell voltage shows that for the FEC/DEC electrolyte without additive the $\mathrm{POF}_{3}$ evolution starts clearly below $4 \mathrm{~V}$, whereas there is a clear delay in the presence of TMSPi $(\sim 4.1 \mathrm{~V})$ and TMSPa $(\sim 4.3 \mathrm{~V})$ (cf. see Figure S2). Especially in the case of the blank electrolyte, two processes may be readily distinguishable during the first cycle. The first process onsets at $3.7 \mathrm{~V}$, is only present in the first cycle, and thus may be ascribed to the oxidation of cell impurities. The second process dominates at cell voltages above $4.3 \mathrm{~V}$ when also oxygen release from the material is initiated. The oxygen release leads to electrolyte oxidation and acidification and subsequently to the formation of $\mathrm{PF}_{5}$ and $\mathrm{POF}_{3}$.

Integration of the $\mathrm{POF}_{3}$ in the first cycle (see Figure $3 \mathrm{~A}$ ) shows about three times more gas for the blank electrolyte (6.9 $\left.\pm 1.5 \mu \mathrm{mol} \mathrm{g}{ }^{-1}\right)$ compared to the electrolytes containing TMSPa $\left(2.1 \pm 0.1 \mu \mathrm{mol} \mathrm{g}^{-1}\right)$ or TMSPi $\left(1.8 \pm 0.7 \mu \mathrm{mol} \mathrm{g}^{-1}\right)$ and about two times more for the second cycle $(3.3 \pm 0.7$ $\mu \mathrm{mol} \mathrm{g}{ }^{-1}$ vs $1.3 \pm 0.3 \mu \mathrm{mol} \mathrm{g}^{-1}(\mathrm{TMSPa}) / 1.4 \pm 0.3 \mu \mathrm{mol}$ $\left.\mathrm{g}^{-1}(\mathrm{TMSP})\right)$. However, $\mathrm{POF}_{3}$ is overall only a minor contributor to the overall gassing in the first two cycles, and its amount is about five times lower than that for $\mathrm{O}_{2}(55 \pm 5$ $\left.\mu \mathrm{mol} \mathrm{g}{ }^{-1}\right)$ and 47 times lower than that for $\mathrm{CO}_{2}(471 \pm 27$

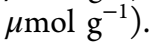

The total amount of $\mathrm{POF}_{3}$ evolved in the first 2 cycles $(\sim 0.27 \pm 0.03 \mu \mathrm{mol})$ corresponds only to a minor part $(\sim 0.2 \%)$ of $\mathrm{LiPF}_{6}$ salt $(\sim 120 \mu \mathrm{mol})$ initially present in the cell. However, if the $\mathrm{POF}_{3}$ rate keeps evolving constantly during 
cycling with the same rate as that observed for the second cycle, all $\mathrm{LiPF}_{6}$ present in our cell will be decomposed after $\sim 1330$ cycles. Although the $\mathrm{POF}_{3}$ evolution rate is reduced in subsequent cycles, ${ }^{32}$ these experiments clearly show that $\mathrm{LiPF}_{6}$ salt decomposition is not only an issue with respect to the formation of HF but also with respect to the loss in ion conductivity of the electrolyte for long cycle life. The addition of either TMSPa or TMSPi strongly suppresses the formation of $\mathrm{POF}_{3}$ and only about one-third (see Figure $3 \mathrm{~A}$ ) of the amount in the blank electrolyte is determined in the first and second cycles when one of the additives is present. This demonstrates the effective mitigation of early salt decomposition and acidification of the electrolyte by adding TMSPx.

As $\mathrm{Me}_{3} \mathrm{SiF}$ stems from the $-\mathrm{SiMe}_{3}$ moiety of TMSPi or TMSPa there is no $\mathrm{Me}_{3} \mathrm{SiF}$ evolution observed in the blank electrolyte. The $\mathrm{Me}_{3} \mathrm{SiF}$ evolution in the FEC/DEC electrolyte with TMSPa was analyzed in detail in our previous study in which we were able to assign the three evolution maxima occurring during the first charge to different processes such as $\mathrm{LiF}$ formation due to $\mathrm{FEC}$ reduction $(\sim 3.5 \mathrm{~V}), \mathrm{H}^{+}$and $\mathrm{HF}$ formation due to oxidation of (surface) impurities ( $4.3-4.4$ $\mathrm{V}$ ), and further $\mathrm{H}^{+}$formation due to electrolyte oxidation by reactive singlet oxygen released from the active material (4.7 $\mathrm{V}){ }^{32}$ In the second cycle only the last maximum is observed, which occurs in parallel with the evolution maxima for $\mathrm{CO}_{2}$ and $\mathrm{POF}_{3}$. If we compare the $\mathrm{Me}_{3} \mathrm{SiF}$ evolution for TMSPa with the one for TMSPi (see Figure 2A) we can still see a clear $\mathrm{Me}_{3} \mathrm{SiF}$ evolution maximum at the end of charge although its evolution rate is significantly lower than for the TMSPa containing electrolyte ( 0.05 vs $\left.0.26 \mu \mathrm{mol} \mathrm{min} \mathrm{m}^{-1} \mathrm{~g}^{-1}\right)$.

The lower evolution rates for the TMSPi containing electrolyte result in overall lower gas amounts in both cycles. In the first cycle the TMSPa containing electrolyte forms over three times more $\mathrm{Me}_{3} \mathrm{SiF}\left(143 \pm 17 \mu \mathrm{mol} \mathrm{g}^{-1}\right.$ vs $39 \pm 12 \mu \mathrm{mol}$ $\mathrm{g}^{-1}$ ), and in the second cycle the gas formation is even more than 7 times higher $\left(44 \pm 3 \mu \mathrm{mol} \mathrm{g}^{-1}\right.$ vs $\left.6 \pm 1 \mu \mathrm{mol} \mathrm{g}^{-1}\right)$. In total, during the OCP period and the first two galvanostatic cycles, $2.5 \pm 0.8 \mu \mathrm{mol}$ of $\mathrm{Me}_{3} \mathrm{SiF}$ were detected for TMSPi in contrast to $4.7 \pm 0.6 \mu \mathrm{mol}$ for TMSPa. For $120 \mu \mathrm{L}$ of FEC/ DEC electrolyte containing 1 wt $\%$ of the additive this corresponds to a conversion of $18 \pm 6 \%$ of TMSPi and $35 \pm$ $4 \%$ for TMSPa (assuming three reactive sites for the additives) into $\mathrm{Me}_{3} \mathrm{SiF}$. For TMSPa, about $8 \%$ of the additive reacts to $\mathrm{Me}_{3} \mathrm{SiF}$ during the second cycle, which means that it would take at least 10 cycles to fully convert all silyl groups from TMSPa to $\mathrm{Me}_{3} \mathrm{SiF}$. However, in the case of TMSPi it must also be assumed that due to the fast reactivity toward $\mathrm{LiPF}_{6}{ }^{36}$ parts of $\mathrm{Me}_{3} \mathrm{SiF}$ already escaped during the cell assembly, so the amount of reacted TMSPi is very likely underestimated. This also makes it difficult to give any assumptions about how long it would take until all TMSPi has reacted.

III.3. Gas Evolution during Cycling: EC/DEC Electrolyte. In a second set of experiments HENCM/graphite cells were cycled in EC/DEC electrolyte (12:88, $1 \mathrm{M} \mathrm{LiPF}$ ) without additive (blank) or with either $1 \mathrm{wt} \% \mathrm{TMSPa}$ or $1 \mathrm{wt}$ $\%$ TMSPi, respectively. Figure $2 \mathrm{~B}$ shows representative curves for the $\mathrm{H}_{2}, \mathrm{CO}_{2}, \mathrm{O}_{2}, \mathrm{POF}_{3}$, and $\mathrm{Me}_{3} \mathrm{SiF}$ evolution for the EC based electrolytes. Please note that during the reduction of EC also $\mathrm{C}_{2} \mathrm{H}_{4}$ is formed; however, as its formation is well understood and described ${ }^{31,43,44}$ it is not discussed in this study.

Also for EC based electrolytes the mechanisms for the evolution of $\mathrm{H}_{2}$ and $\mathrm{O}_{2}$ were already discussed in detail in previous works. ${ }^{31,37,45}$ No apparent difference in the gas evolution profiles from the earlier works is observed for these two gases. If we compare the evolution profiles between the three EC based electrolytes, it can be easily seen that there is no major difference. There is also no apparent difference between the evolution profiles for these two gases between the FEC based and the EC based electrolytes.

In contrast to the FEC based electrolyte there are clear differences in the $\mathrm{CO}_{2}$ evolution profile for the $\mathrm{EC}$ based electrolytes. While all three electrolytes show the same features, namely, a first peak in the evolution at about 4.35 $\mathrm{V}$, which is only observed in the first cycle, followed by a maximum evolution at the cutoff voltage of $4.7 \mathrm{~V}$, the evolution rate for the electrolyte with TMSPi is significantly lower compared with the others. For example, during the first evolution peak at about $4.35 \mathrm{~V}$ the $\mathrm{CO}_{2}$ evolution rate for the TMSPi based electrolyte is only $0.13 \mu \mathrm{mol} \mathrm{min} \mathrm{m}^{-1} \mathrm{~g}^{-1}$ and thus clearly lower than both the blank electrolyte $\left(0.22 \mu \mathrm{mol} \mathrm{min}^{-1}\right.$ $\left.\mathrm{g}^{-1}\right)$ as well as the one containing TMSPa $\left(0.19 \mu \mathrm{mol} \mathrm{min}^{-1}\right.$ $\left.\mathrm{g}^{-1}\right)$. The significantly lower evolution rate is observed all over the first two cycles and subsequently results in a lower amount of $\mathrm{CO}_{2}\left(121 \pm 10 \mu \mathrm{mol} \mathrm{g}^{-1}\right)$ for the TMSPi based electrolyte compared to the blank $\left(246 \pm 42 \mu \mathrm{mol} \mathrm{g}^{-1}\right)$ and the TMSPa containing one $\left(208 \pm 9 \mu \mathrm{mol} \mathrm{g}^{-1}\right)$.

Significant differences were also observed for the formation of $\mathrm{POF}_{3}$. For all three EC based electrolytes the evolution profile for $\mathrm{POF}_{3}$ only shows one major feature which is the maximum at the cutoff voltage of the cell at $4.7 \mathrm{~V}$. The presence of TMSPa or TMSPi leads also for the EC based electrolytes to a suppression of $\mathrm{POF}_{3}$ evolution; thus, the evolution rate at $4.7 \mathrm{~V}$ is for TMSPi $\left(4 \mathrm{nmol} \mathrm{min} \mathrm{mg}^{-1} \mathrm{~g}^{-1}\right)$ and TMSPa $\left(10 \mathrm{nmol} \mathrm{min}{ }^{-1} \mathrm{~g}^{-1}\right)$ about one-third that of the blank electrolyte $\left(26 \mathrm{nmol} \mathrm{min} \mathrm{g}^{-1}\right)$. Additionally, for TMSPa containing electrolyte a constant but very low $\mathrm{POF}_{3}$ evolution ( $\max .1 .2 \mathrm{nmol} \mathrm{min}{ }^{-1} \mathrm{~g}^{-1}$ ) was observed directly after the SEI formation until the onset of the high voltage maximum.

Comparison of the integrated gas amounts (Figure 4) shows that there is no significant difference between the blank EC based electrolyte $\left(0.9 \pm 0.6 \mu \mathrm{mol} \mathrm{g}^{-1}\right)$ and the one containing TMSPa $\left(1.0 \pm 0.2 \mu \mathrm{mol} \mathrm{g}^{-1}\right)$ in the first cycle, whereas in the second cycle, in which only the high voltage $\mathrm{POF}_{3}$ maximum is observed for both electrolytes, the blank electrolyte releases more $\mathrm{POF}_{3}\left(0.9 \pm 0.5 \mu \mathrm{mol} \mathrm{g}{ }^{-1}\right)$ than the TMSPa containing electrolyte $\left(0.3 \pm 0.1 \mu \mathrm{mol} \mathrm{g}^{-1}\right)$. For both cycles the lowest amount of $\mathrm{POF}_{3}$ is however produced with the EC based electrolyte containing TMSPi $\left(0.4 \pm 0.2 \mu \mathrm{mol} \mathrm{g}^{-1}\right.$ ( 1 st cycle); $0.2 \pm 0.1 \mu \mathrm{mol} \mathrm{g}^{-1}$ (2nd cycle)). In all cases the EC based electrolytes produced significantly less $\mathrm{POF}_{3}$ than their FEC based counterparts.

Also for the EC based electrolyte the formation of $\mathrm{Me}_{3} \mathrm{SiF}$ is observed in electrolytes containing TMSPa or TMSPi. For the one containing TMSPa the evolution profile of $\mathrm{Me}_{3} \mathrm{SiF}$ during the first charge has been discussed in detail in our previous study. ${ }^{32}$ As for the FEC based electrolyte three potential dependent evolution peaks are observed (cf. Figure 2). In the second cycle only the evolution maximum $\left(0.26 \mu \mathrm{mol} \mathrm{min}^{-1}\right.$ $\mathrm{g}^{-1}$ ) at $4.7 \mathrm{~V}$ is observed. For TMSPi no distinguishable potential dependent evolution maxima can be identified during the first cycle due to the strong gas evolution in the resting period. Nonetheless, in the second cycle a small evolution maximum $\left(0.02 \mu \mathrm{mol} \mathrm{min}{ }^{-1} \mathrm{~g}^{-1}\right)$ is observed at $4.7 \mathrm{~V}$ showing that TMSPi or decomposition products thereof are still undergoing reactions at these voltages. The gassing of 
$\mathrm{Me}_{3} \mathrm{SiF}$ during cycling with TMSPi as additive is also about four times lower than for the electrolyte containing TMSPa (see Figure 4).

Comparison of the absolute $\mathrm{Me}_{3} \mathrm{SiF}$ amounts in FEC based electrolytes (TMSPi: $2.5 \pm 0.8 \mu \mathrm{mol}$; TMSPa: $4.7 \pm 0.6$ $\mu \mathrm{mol})$ ) with the ones in EC based electrolytes (TMSPi: $2.7 \pm$ $0.3 \mu \mathrm{mol}$; TMSPa: $3.1 \pm 0.2 \mu \mathrm{mol}$ ) shows that the gas amount measured is largely independent from the cyclic carbonate used in the electrolyte formulation. Additionally, the cyclic carbonate used does not have a major impact on the extent of the conversion of the TMSPi additive into gaseous $\mathrm{Me}_{3} \mathrm{SiF}$ (FEC: $18 \pm 6 \%$; EC: $20 \pm 2 \%$ ). However, for TMSPa there is significant influence, which can probably be assigned to the formation of $\mathrm{LiF}$ during $\mathrm{FEC}$ reduction, resulting in a lower conversion to $\mathrm{Me}_{3} \mathrm{SiF}$ in the EC based electrolyte $(23 \pm 2 \%)$ compared to the FEC based one $(35 \pm 4 \%)$.

III.4. Further Analytical Data. Based on gas analysis with OEMS and cyclic voltammetry measurements we have recently concluded that there is no oxidation of the TMSPa additive in FEC based electrolytes and also no formation of a surface layer which should result in suppressed formation of $\mathrm{CO}_{2}{ }^{32}$ Analysis of the surface of HE-NCM electrodes in in EC:DEC (12:88) 1 $\mathrm{M} \mathrm{LiClO}_{4}$ containing 0 or 1 wt \% TMSPa (Supporting Information Figure S3) confirmed the absence of any surface layer formed due to TMSPa oxidation.

OEMS analysis of FEC electrolyte based cells containing TMSPi shows that there is also no significant suppression of $\mathrm{CO}_{2}$, and thus the formation of a SPI which effectively prevents electrolyte decomposition is unlikely for HE-NCM. However, cyclic voltammetry on carbon electrodes showed significantly higher currents $>4.5 \mathrm{~V}$ vs $\mathrm{Li}^{+} / \mathrm{Li}$ for electrolyte containing TMSPi (see Figure S4) which is in contrast to theoretical studies by Kim et al., who predict a stability for TMSPi similar to that for TMSPa. ${ }^{24}$ The additional oxidative current is rather high and would correspond to $>3 \mathrm{e}^{-} /$TMSPi. As discussed in the previous section, the low chemical stability of TMSPi in the 12:88 electrolytes makes it doubtful if there is still a significant amount of TMSPi present in the electrolyte when the cell reaches high cell voltages. We therefore hypothesize that not TMSPi itself, but rather a decomposition product of it, undergoes the observed electrochemical oxidation. Gas analysis by OEMS that was performed during the CV experiments did not provide any further information about the products of this oxidation reaction.

\section{DISCUSSION}

IV.1. Stability of TMSPi/a in $\mathrm{LiPF}_{6}$ Containing Electrolytes. A major difference between TMSPa and TMSPi is the reactivity toward the $\mathrm{LiPF}_{6}$ salt in the electrolyte which could be observed in the form of $\mathrm{Me}_{3} \mathrm{SiF}$ and $\mathrm{POF}_{3}$ release during the initial $4 \mathrm{~h}$ resting period. While the TMSPa containing electrolytes show hardly any evolution of $\mathrm{Me}_{3} \mathrm{SiF}$ during the early rest period, the electrolytes with TMSPi release significant amounts of $\mathrm{Me}_{3} \mathrm{SiF}$, and their evolution rates decay exponentially directly after attachment of the cell to the OEMS setup. This observation is a result of the already described reactivity of the TMSPi additive toward the $\mathrm{PF}_{6}{ }^{-}$ anion, which leads to the decomposition of the additive and the salt. ${ }^{36}$ The high initial amount of $\mathrm{Me}_{3} \mathrm{SiF}$, the evolution of some $\mathrm{POF}_{3}$ or $\mathrm{PF}_{5}$, and the low amounts released during cycling indicate that an immediate reaction of TMSPi with the $\mathrm{PF}_{6}{ }^{-}$anion is taking place once the additive is added to the base electrolyte. One could hypothesize that the free electron pair of TMSPi allows for the coordination of the Lewis acid $\mathrm{PF}_{5}$ and that the close proximity of $\mathrm{F}-$ and $\mathrm{Me}_{3} \mathrm{Si}-$ leads to the cleavage of one or several $\mathrm{Me}_{3} \mathrm{SiF}$ from this complex.

For the LP47 electrolyte used by Qi et al., ${ }^{36}$ which has a 3:7 (w/w) EC/DEC ratio, the reactivity toward the $\mathrm{LiPF}_{6}$ salt is much slower (hardly any evolution of $\mathrm{Me}_{3} \mathrm{SiF}$ during the resting period for the freshly prepared electrolyte, cf. Figure S1). In contrast the electrolytes containing only $12 \%$ (F)EC show a higher reactivity toward the $\mathrm{PF}_{6}^{-}$anion which is an effect of the lower content of the cyclic carbonate. Borodin et al. showed by DFT calculations that highly EC coordinated $\mathrm{Li}^{+}$ cations are energetically more favored, with the 4-fold coordinated as the most stable complex. ${ }^{46}$ Other theoretical studies ${ }^{47,48}$ or experimental studies ${ }^{49}$ indicate that the $\mathrm{Li}^{+}$ might even be coordinated by up to 5 or 6 cyclic carbonate molecules. However, in an (F)EC/DEC (12:88) electrolyte with $1 \mathrm{M} \mathrm{LiPF}_{6}$ the ratio $(\mathrm{F}) \mathrm{EC}: \mathrm{Li}^{+}$is only about $1.6: 1$ (compare Figure S5). Therefore, it can be assumed that not all $\mathrm{Li}^{+}$are coordinated by cyclic carbonates and $\mathrm{LiPF}_{6}$ occurs partly as a contact ion pair as was observed for $\mathrm{LiClO}_{4}$ in pure DEC $^{50}$ A recent MD simulation by Hou et al. shows also that coordination to $\mathrm{Li}^{+}$is weaker for FEC than for EC which leads to a higher extent of contact-ion pairs in FEC based electrolytes. ${ }^{47}$ In a contact-ion pair, the direct coordination of $\mathrm{Li}^{+}$to the $\mathrm{PF}_{6}{ }^{-}$anion weakens the $\mathrm{P}-\mathrm{F}$ bonds and makes it thus more reactive toward the additives. Therefore, the stabilities of TMSPi and TMSPa are strongly dependent on the composition of the electrolyte.

However, even for electrolytes with higher EC content such as LP47, the 4 day aged solution with 1 wt \% TMSPi only shows $\mathrm{Me}_{3} \mathrm{SiF}$ evolution during the OCP but no potential dependent gas formation during cycling, indicating that all TMSPi is consumed, forming a less reactive compound. This high reactivity of TMSPi makes it questionable if the additive itself or decomposition products thereof cause the reported long-term effects of TMSPi. A detailed study about TMSPi decomposition products in electrolyte solutions containing 10 wt $\%$ additive was conducted by Peebles et al. ${ }^{25}$ They identified the aging product $\mathrm{F}_{2} \mathrm{POSiMe}_{3}$ as the effective additive in their system (NCM523) as it is able to bind to NCM surfaces. In general, despite its positive effects of HF scavenging, some reaction products of TMSPi might even be more desirable additives.

IV.2. Main Operation Mechanism of TMSPa/TMSPi in the FEC Based Electrolyte. All of the working mechanisms of TMSPx listed in the Introduction should influence the gas evolution during cycling, and OEMS should thus allow us to study which of these processes play a role in the studied systems. Formation of a protective surface layer which effectively prevents electrolyte decomposition should result in decreased electrolyte oxidation and thus less $\mathrm{CO}_{2}$ evolution. Additionally an oxidative current should be observable if the surface layer is formed due to additive oxidation. The complexation of the surface should also lead to decreased formation of $\mathrm{CO}_{2}$ and, in the case of a stabilization of the surface, less $\mathrm{O}_{2}$ release. The latter should also be observed in the case of $\mathrm{O}$ scavenging, whereas $\mathrm{HF} / \mathrm{POF}_{3}$ scavenging should result in decreased $\mathrm{POF}_{3}$ formation and, in the case of $\mathrm{HF}$ scavenging, the evolution of $\mathrm{Me}_{3} \mathrm{SiF}$.

The absence of any suppressed $\mathrm{CO}_{2}$ evolution for TMSPa and TMSPi, despite the observation of an oxidative current for the latter in the $\mathrm{CV}$ experiments, indicates that any surface 
layer formed is not effectively preventing reactions which lead to electrolyte oxidation and $\mathrm{CO}_{2}$ formation.

The OEMS data also show that there is no suppression of $\mathrm{O}_{2}$ evolution by TMSPi, thus indicating that TMSPi is not acting as an oxygen scavenger. In addition, it can be also excluded that a coordination of TMSPx additive or its respective decomposition products coordinate the surface in a manner that leads to a significant stabilization of the CAM surface and suppresses formation of a rock-salt surface layer during the initial cycles.

Similar to TMSPa, the main effect of TMSPi in the FEC based electrolyte as can be observed by OEMS is also the suppression of the formation of $\mathrm{POF}_{3} / \mathrm{PF}_{5}$ as can be seen from the clearly suppressed evolution rates and amounts (cf. Figure 2). As mentioned above, $\mathrm{POF}_{3}$ and $\mathrm{PF}_{5}$ cannot be distinguished in the MS and are measured as a fragment of $\mathrm{POF}_{3}$. However, the study from Solchenbach et al. shows that the source of it is very likely $\mathrm{PF}_{5}$ which is formed due to acidification of the electrolyte. ${ }^{35}$ The suppression of $\mathrm{POF}_{3}$ formation for TMSPx can be therefore attributed to the decrease of the acidity in the electrolyte by the additives. In our previous manuscript, we already discussed this mechanism for TMSPa and that it goes in parallel with the evolution of $\mathrm{Me}_{3} \mathrm{SiF}^{32}$ The resulting phosphoric acid derivate is less prone to releasing the proton compared to HF, which is always in equilibrium with $\mathrm{Li}^{+}$to form $\mathrm{LiF}$ and a "free" $\mathrm{H}^{+}$(see Figure 5).

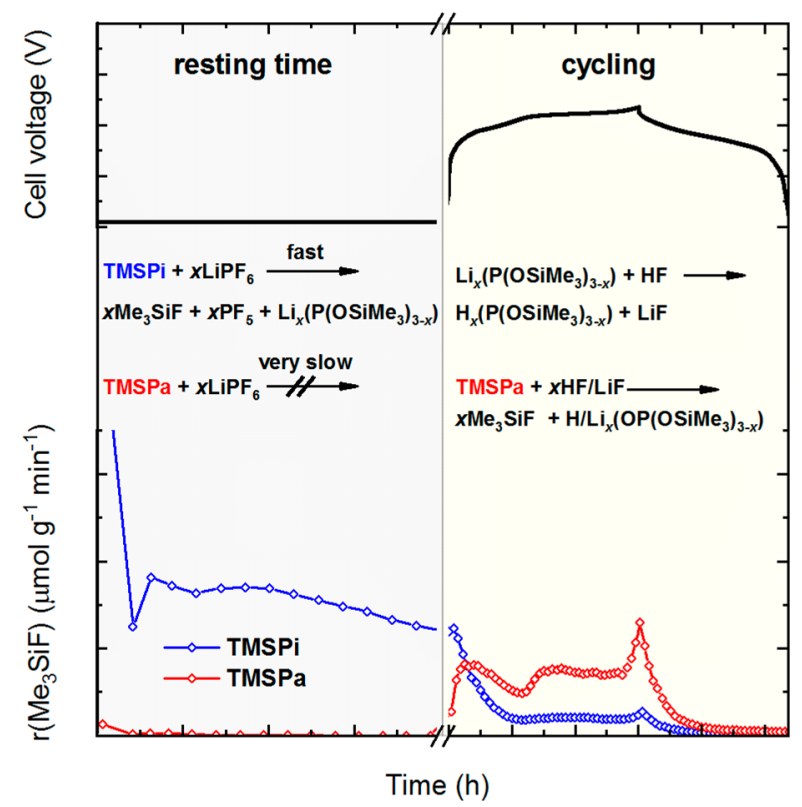

Figure 5. Reaction scheme visualizing the different reactivities of TMSPa and TMSPi with $\mathrm{LiPF}_{6}$ and $\mathrm{LiF}$ and $\mathrm{HF}$ leading to different $\mathrm{Me}_{3} \mathrm{SiF}$ evolution profiles.

However, in contrast to TMSPa there is hardly any potential dependent formation of $\mathrm{Me}_{3} \mathrm{SiF}$ observed for TMSPi and the amount of $\mathrm{Me}_{3} \mathrm{SiF}$ released during the first cycle is significantly lower, most of which probably stems from the initial $\mathrm{Me}_{3} \mathrm{SiF}$ formation during the OCP period. Therefore, the mechanism for how TMSPi prevents the acidification must differ slightly. The initial reactions of TMSPi with the $\mathrm{LiPF}_{6}$ salt as observed here and first descibed by Qi et al. leads to the formation of partly soluble Li-phosphites, ${ }^{36}$ which is mainly taking place during the initial resting period (left half of Figure 5). We hypothesize that, during the cycling, when HF is formed due to oxidation of electrolyte and surface groups, the formed HF can react with the $\mathrm{Li}$-phosphites which would lead to the formation of $\mathrm{LiF}$ and phosphoric acid derivate. Due to the low solubility of $\mathrm{LiF}$ this equilibrium would be pushed toward $\mathrm{LiF}$ and thus the acidification of the electrolyte and the formation of $\mathrm{POF}_{3} /$ $\mathrm{PF}_{5}$ could be prevented even in the absence of the formation of significant amounts of $\mathrm{Me}_{3} \mathrm{SiF}$ during the first cycle. A summarized scheme of this reaction is presented in Figure 5.

IV.3. Main Operation Mechanism of TMSPa/TMSPi in the EC Based Electrolyte. In the EC based electrolyte some of the effects of the additives observed by OEMS partly vary from the observations made for the FEC based electrolytes. However, for $\mathrm{O}_{2}$ no difference in the released amount is observed thus supporting the conclusion that the $\mathrm{P}$ (III) atom in TMSPi is not acting as scavenger for $\mathrm{O}_{2}$ and that none of the additives is complexing the CAM surface in a manner that it is stabilized and the surface reconstruction suppressed.

However, the presence of TMSPi in EC/DEC electrolyte leads to a clear suppression of $\mathrm{CO}_{2}$ evolution compared to blank electrolyte as well as the one containing TMSPa (see Figure $2 \mathrm{~B}$, an additional version of this figure showing only the relevant $\mathrm{CO}_{2}$ evolution is provided in the SI in Figure S6). Interestingly, the suppression of the $\mathrm{CO}_{2}$ formation is already very pronounced before ( 0.07 (blank) vs 0.02 (TMSPi) $\mu \mathrm{mol}$ $\min ^{-1} \mathrm{~g}^{-1}$ at $\left.4.0 \mathrm{~V}\right)$ and during the activation plateau in the

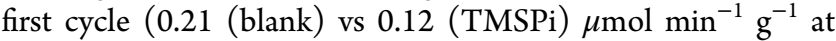
$4.4 \mathrm{~V}$ ). However, the formation of an SPI, as proposed by several groups, ${ }^{7,9,11,15-22}$ should occur at a certain voltage until which $\mathrm{CO}_{2}$ release should be similar to the blank electrolyte and after which it should be suppressed. However, $\mathrm{CO}_{2}$ suppression already occurs before any additional current is observed ( $>4.5 \mathrm{~V}$ in the CV experiment, see Figure S4), so that the oxidation of TMSPi (or its decomposition products) is not the key step in $\mathrm{CO}_{2}$ suppression. Keeping in mind that the only component that was changed was the cyclic carbonate, it seems much more likely that TMSPi is acting again as a chemical scavenger. As was shown by Metzger et al., EC is sensitive toward hydrolysis, especially under basic conditions which can occur in a LIB, e.g., due to the formation of alkoxides during the SEI formation, and that this hydrolysis leads to the formation of $\mathrm{CO}_{2}{ }^{51}$ Also the trivalent phosphoric acid esters such as $\mathrm{P}(\mathrm{OMe})_{3}$ are known to undergo hydrolysis under such conditions ${ }^{52}$ and are doing that at faster rate than the respective phosphates. The suppression of $\mathrm{CO}_{2}$ could therefore be an indication that TMSPi is able to suppress hydrolysis of EC and acts as scavenger not only for HF but also for hydroxides and alkoxides in LIBs. This is supported by calculations from Yim and Han who found the reaction of $\mathrm{Li}^{+}$ coordinated TMSPi with $\mathrm{MeO}^{-}$energetically more favored than the reaction of EC. ${ }^{28}$

The $\mathrm{POF}_{3}$ amounts presented in Figure 4, especially during the second cycle, indicate that also in EC based electrolytes the TMSPa and TMSPi additives suppress the formation of $\mathrm{POF}_{3}$ by scavenging $\mathrm{HF}$ and thus lower the acidity in the electrolyte. However, the amount of $\mathrm{POF}_{3}$ formed in the blank EC based electrolyte is much lower than in the FEC based one (seven times for the first cycle and three times for the second cycle, respectively); therefore, the HF scavenging effect of the additives is much less pronounced. This indicates that the cyclic carbonate has a strong influence on the reactivity of the 
electrolyte salt, which will be discussed in the subsequent paragraph.

Overall, the observed effects on the gas evolution in EC based electrolytes by the TMSPi and TMSPa additive indicate that also in this system surface layers do not lead to an effective prevention of electrolyte oxidation and thus gassing and that the main effects result from chemical scavenging, in the case of TMSPa solely of fluorides and for TMSPi both fluorides and possibly alkoxides.

IV.4. Stability of the Conductive Salt in FEC Based Electrolytes vs the EC Based Electrolyte. In a previous study from our group, Streich et al. reported significant differences in the formation of $\mathrm{POF}_{3}$ between EC based and FEC based electrolytes containing $30 \mathrm{wt} \%$ of cyclic carbonate $^{31}$ in a similar manner as is observed in this study with the 12:88 composition. Streich et al. suggested that $\mathrm{POF}_{3}$ is formed by the reaction of $\mathrm{PF}_{5}$ with $\mathrm{Li}_{2} \mathrm{CO}_{3}$, the latter formed either in the cell by $\mathrm{CO}_{2}$ reduction or present as impurity on the CAM, and that differences in the electrolyte composition affect either the solubility of $\mathrm{Li}_{2} \mathrm{CO}_{3}$ or the concentration of $\mathrm{PF}_{5}{ }^{31}$ However, the authors could not reach a final conclusion about this matter.

In the meantime, new studies allow us to cast new light on this open question. A recent study from Solchenbach et al. shows that a significant amount of $\mathrm{POF}_{3}$ detected by MS is in fact $\mathrm{PF}_{5}$ which reacts on its way to the ionization source with surfaces of the setup. ${ }^{35}$ It was also shown that a main contributor to the formation of $\mathrm{PF}_{5} / \mathrm{POF}_{3}$ in OEMS experiments is not the content of water impurities but protons in the electrolyte which subsequently lead to the further formation of $\mathrm{PF}_{5}$ in a self-sustaining loop as described by Plakhotnyk et al. ${ }^{53}$ A further study by Kim et al. showed that FEC is labile toward attacks by strong Lewis acids, which can lead to the formation of vinylene carbonate and protons. ${ }^{54}$

We therefore propose that, in FEC containing electrolytes, a combination of these two processes is taking place (cf. Figure 6): (1) Electrochemically initiated deprotonation of carbonate

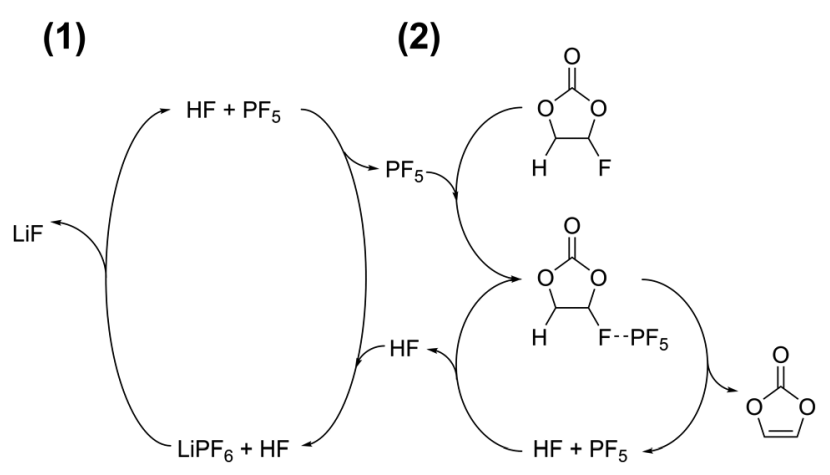

Figure 6. Schematic for the $\mathrm{PF}_{5}$ driven decomposition cycle in FEC based electrolytes.

electrolytes leads to the formation of $\mathrm{HF}$ that decomposes $\mathrm{LiPF}_{6}$ into $\mathrm{LiF}, \mathrm{HF}$, and $\mathrm{PF}_{5}$. HF in turn decomposes more salt as suggested by Solchenbach et al. and Plakhotnyk et al. ${ }^{53}$ (2) The thus formed $\mathrm{PF}_{5}$ dehydrofluorinates catalytically the FEC leading to even more $\mathrm{HF}$ (which can subsequently attack further electrolyte salt), and VC as products similar to the reaction described by Kim et al. ${ }^{54}$ or polymeric species as described by $\mathrm{Xu}$ et al. ${ }^{55}$ The second part of this mechanism, the attack on the cyclic carbonate, cannot take place in EC based electrolytes, and the lower acidification of the electrolyte can thus explain the observed differences in the $\mathrm{POF}_{3}$ evolution between the two electrolytes. The presence of an HF scavenging additive such as TMSPa or TMSPi in FEC based electrolytes is therefore crucial to reduce the acidity in the electrolyte and, thus, prevent the $\mathrm{PF}_{5}$ formation and subsequent FEC dehydrofluorination, allowing longer cycling life as shown in the long term cycling experiments (cf. Supporting Information Figure S7).

\section{CONCLUSIONS}

Our complementary OEMS studies on gas evolved during cycling of HE-NCM full cells with $1 \mathrm{M} \mathrm{LiPF}_{6}$ in FEC:DEC (12:88) or EC:DEC $(12: 88)$ containing 0 or 1 wt \% TMSPa or TMSPi provide further understanding of the reactivity of TMSPa and TMSPi in the Li-ion cell.

1. A main operation mechanism of TMSPa and TMSPi in EC and FEC based electrolytes is HF scavenging and reduction of electrolyte acidity as is shown by the formation of $\mathrm{Me}_{3} \mathrm{SiF}$ and the decreased evolution of $\mathrm{POF}_{3}$ in electrolytes containing one of the additives. The reduced acidification of the electrolyte leads subsequently to less transition metal dissolution and more stable cathode surfaces, which were observed in previous studies but exclusively assigned to the formation of a passivating surface layer.

2. The interface layers observed in previous study in the presence of TMSPx additives do not display significant impact to affect the $\mathrm{O}_{2}$ and $\mathrm{CO}_{2}$ evolution which indicates that they only have limited impact on suppressing these side reactions.

3. Only for EC based electrolyte containing TMSPi was a lower amount of $\mathrm{CO}_{2}$ observed. However, decreased $\mathrm{CO}_{2}$ formation occurs already at low cell voltages and not close to the high cutoff voltage where it would be expected in case of the formation of a protective interface. Our hypothesis is that TMSPi due to its reactive $\mathrm{P}$ (III) atom also scavenges hydroxide and alkoxide and thus prevents the hydrolysis of $\mathrm{EC}$ which is observed under alkaline conditions.

4. TMSPi is effective in suppressing the formation of $\mathrm{PF}_{5} /$ $\mathrm{POF}_{3}$ despite its high reactivity toward the $\mathrm{PF}_{6}{ }^{-}$anion. The finding is supported by other studies showing that not TMSPi but one of its decomposition products effectively enhances long-term stability. The findings suggest that previous studies of the electrochemical stability of these additives need to be reevaluated with the respect to the chemical reactivity of the TMSPx.

5. Comparison between TMSPa and TMSPi and electrolytes with different contents of (F)EC shows that the TMSPi additive undergoes side reactions with the electrolyte much faster than the TMSPa additive. The rate of this side reaction also depends on the content of the cyclic carbonate and takes place much faster in electrolytes with a low content of cyclic carbonate. Likely, the formation of contact-ion pairs in electrolytes with low cyclic carbonate amounts promotes chemical kinetics of the reactions.

6. Previous observations of a higher content of $\mathrm{POF}_{3}$ in FEC based electrolytes compared to identical formulations containing EC were confirmed. However, our findings let us conclude that this is likely an effect of the 
instability of FEC toward $\mathrm{PF}_{5}$ that is formed under acidic conditions in the cell. Therefore, for long-term cycling in FEC containing electrolytes the usage of $\mathrm{HF}$ / $\mathrm{H}^{+}$scavengers is recommended. Despite the higher oxidative stability, FEC based electrolytes lead to the formation of more $\mathrm{CO}_{2}$ during the SEI formation. This source of gas evolution could be suppressed by adding a suitable additive which is reduced at higher potentials compared to the electrolyte formulation.

\section{ASSOCIATED CONTENT}

\section{S Supporting Information}

The Supporting Information is available free of charge at https://pubs.acs.org/doi/10.1021/acsaem.9b01551.

OEMS data during OCV in LP47; figure on the potential dependence of $\mathrm{POF}_{3}$ release; calculation of the $\mathrm{Li}^{+} / \mathrm{F}(\mathrm{EC})$ ratio; XPS data of HE-NCM electrodes after 2 cycles; $\mathrm{CV}$ data for EC and FEC based electrolytes; and long-term cycling data for FEC/DEC electrolytes (PDF)

\section{AUTHOR INFORMATION}

\section{Corresponding Author}

*(C.B.) E-mail: christoph.bolli@psi.ch.

ORCID $\odot$

Christoph Bolli: 0000-0002-3278-8467

Erik J. Berg: 0000-0001-5653-0383

Present Address

"(E.J.B.) Department of Chemistry, Ångström Laboratory, Uppsala University, Box 538, SE-751 21 Uppsala, Sweden.

\section{Author Contributions}

$\S$ (A.G. and C.B.) These authors contributed equally.

\section{Funding}

Funding by BASF SE is gratefully acknowledged. E.J.B. acknowledges Swiss National Science Foundation (SNSF) under the "Ambizione Energy" funding scheme (Grant No. 160540).

\section{Notes}

The authors declare no competing financial interest.

\section{ACKNOWLEDGMENTS}

The authors would like to thank Dr. Minglong $\mathrm{He}$ and Dr. Daniel Streich for fruitful discussions and Hermann Kaiser and Christoph Junker for technical assistance.

\section{REFERENCES}

(1) $\mathrm{Xu}, \mathrm{K}$. Nonaqueous Liquid Electrolytes for Lithium-Based Rechargeable Batteries. Chem. Rev. 2004, 104 (10), 4303-4418.

(2) Zhang, S. S. A review on electrolyte additives for lithium-ion batteries. J. Power Sources 2006, 162 (2), 1379-1394.

(3) Haregewoin, A. M.; Wotango, A. S.; Hwang, B.-J. Electrolyte additives for lithium ion battery electrodes: progress and perspectives. Energy Environ. Sci. 2016, 9 (6), 1955-1988.

(4) El Ouatani, L.; Dedryvère, R.; Siret, C.; Biensan, P.; Reynaud, S.; Iratçabal, P.; Gonbeau, D. The Effect of Vinylene Carbonate Additive on Surface Film Formation on Both Electrodes in Li-Ion Batteries. J. Electrochem. Soc. 2009, 156 (2), A103-A113.

(5) Gallus, D. R.; Wagner, R.; Wiemers-Meyer, S.; Winter, M.; Cekic-Laskovic, I. New insights into the structure-property relationship of high-voltage electrolyte components for lithium-ion batteries using the pKa value. Electrochim. Acta 2015, 184, 410-416.
(6) Tarnopolsky, V. Electrolyte for rechargeable lithium battery, and rechargeable lithium battery including same. US7494746B2, 2009.

(7) Mai, S.; Xu, M.; Liao, X.; Hu, J.; Lin, H.; Xing, L.; Liao, Y.; Li, $\mathrm{X}$.; Li, W. Tris(trimethylsilyl)phosphite as electrolyte additive for high voltage layered lithium nickel cobalt manganese oxide cathode of lithium ion battery. Electrochim. Acta 2014, 147, 565-571.

(8) Sinha, N. N.; Burns, J. C.; Dahn, J. R. Comparative Study of Tris(trimethylsilyl) Phosphate and Tris(trimethylsilyl) Phosphite as Electrolyte Additives for Li-Ion Cells. J. Electrochem. Soc. 2014, 161 (6), A1084-A1089.

(9) Song, Y.-M.; Han, J.-G.; Park, S.; Lee, K. T.; Choi, N.-S. A multifunctional phosphite-containing electrolyte for 5 V-class $\mathrm{LiNi}$.5Mn1.5O4cathodes with superior electrochemical performance. J. Mater. Chem. A 2014, 2 (25), 9506-9513.

(10) Koo, B.; Lee, J.; Lee, Y.; Kim, J. K.; Choi, N.-S. Vinylene carbonate and tris(trimethylsilyl) phosphite hybrid additives to improve the electrochemical performance of spinel lithium manganese oxide/graphite cells at $60^{\circ} \mathrm{C}$. Electrochim. Acta 2015, 173, 750-756.

(11) Song, Y.-M.; Kim, C.-K.; Kim, K.-E.; Hong, S. Y.; Choi, N.-S. Exploiting chemically and electrochemically reactive phosphite

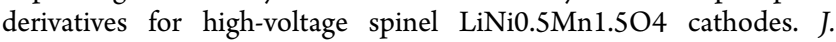
Power Sources 2016, 302, 22-30.

(12) Han, J.-G.; Lee, S. J.; Lee, J.; Kim, J.-S.; Lee, K. T.; Choi, N.-S. Tunable and Robust Phosphite-Derived Surface Film to Protect Lithium-Rich Cathodes in Lithium-Ion Batteries. ACS Appl. Mater. Interfaces 2015, 7 (15), 8319-8329.

(13) Wang, D. Y.; Dahn, J. R. A High Precision Study of Electrolyte Additive Combinations Containing Vinylene Carbonate, Ethylene Sulfate, Tris(trimethylsilyl) Phosphate and Tris(trimethylsilyl) Phosphite in $\mathrm{Li}[\mathrm{Ni} 1 / 3 \mathrm{Mn} 1 / 3 \mathrm{Co} / / 3] \mathrm{O} 2 /$ Graphite Pouch Cells. J. Electrochem. Soc. 2014, 161 (12), A1890-A1897.

(14) Terahara, A.; Yamamoto, T.; Nakane, K. Non-aqueous electrolyte and lithium secondary battery using the same. US6379846B1, 2002.

(15) Zhang, J.; Wang, J.; Yang, J.; NuLi, Y. Artificial Interface Deriving from Sacrificial Tris(trimethylsilyl)phosphate Additive for Lithium Rich Cathode Materials. Electrochim. Acta 2014, 117, 99104.

(16) Yan, G.; Li, X.; Wang, Z.; Guo, H.; Wang, C. Tris(trimethylsilyl)phosphate: A film-forming additive for high voltage cathode material in lithium-ion batteries. J. Power Sources 2014, 248, 1306-1311.

(17) Rong, H.; Xu, M.; Xing, L.; Li, W. Enhanced cyclability of LiNi0.5Mn1.5O4 cathode in carbonate based electrolyte with incorporation of tris(trimethylsilyl)phosphate (TMSP). J. Power Sources 2014, 261, 148-155.

(18) Delp, S. A.; Borodin, O.; Olguin, M.; Eisner, C. G.; Allen, J. L.; Jow, T. R. Importance of Reduction and Oxidation Stability of High Voltage Electrolytes and Additives. Electrochim. Acta 2016, 209, 498510.

(19) Rong, H.; Xu, M.; Xie, B.; Huang, W.; Liao, X.; Xing, L.; Li, W. Performance improvement of graphite/LiNi0.4Co0.2Mn0.4O2 battery at high voltage with added Tris (trimethylsilyl) phosphate. J. Power Sources 2015, 274, 1155-1161.

(20) Zhu, Y.; Luo, X.; Xu, M.; Zhang, L.; Yu, L.; Fan, W.; Li, W. Failure mechanism of layered lithium-rich oxide/graphite cell and its solution by using electrolyte additive. J. Power Sources 2016, 317, 6573.

(21) Han, J. G.; Lee, S. J.; Lee, J.; Kim, J. S.; Lee, K. T.; Choi, N. S. Tunable and robust phosphite-derived surface film to protect lithiumrich cathodes in lithium-ion batteries. ACS Appl. Mater. Interfaces 2015, 7 (15), 8319-29.

(22) Han, Y.-K.; Yoo, J.; Yim, T. Why is tris(trimethylsilyl) phosphite effective as an additive for high-voltage lithium-ion batteries? J. Mater. Chem. A 2015, 3 (20), 10900-10909.

(23) Tornheim, A.; Garcia, J. C.; Sahore, R.; Iddir, H.; Bloom, I.; Zhang, Z. Decomposition of Phosphorus-Containing Additives at a Charged NMC Surface through Potentiostatic Holds. J. Electrochem. Soc. 2019, 166 (4), A440-A447. 
(24) Kim, D. Y.; Park, H.; Choi, W. I.; Roy, B.; Seo, J.; Park, I.; Kim, J. H.; Park, J. H.; Kang, Y.-S.; Koh, M. Ab initio study of the operating mechanisms of tris(trimethylsilyl) phosphite as a multifunctional additive for Li-ion batteries. J. Power Sources 2017, 355, 154-163.

(25) Peebles, C.; Garcia, J.; Tornheim, A. P.; Sahore, R.; Bareño, J.; Liao, C.; Shkrob, I. A.; Iddir, H. H.; Abraham, D. P. Chemical "Pickling" of Phosphite Additives Mitigates Impedance Rise in Li Ion Batteries. J. Phys. Chem. C 2018, 122 (18), 9811-9824.

(26) Peebles, C.; Sahore, R.; Gilbert, J. A.; Garcia, J. C.; Tornheim, A.; Bareño, J.; Iddir, H.; Liao, C.; Abraham, D. P. Tris(trimethylsilyl) Phosphite (TMSPi) and Triethyl Phosphite (TEPi) as Electrolyte Additives for Lithium Ion Batteries: Mechanistic Insights into Differences during LiNi0.5Mn0.3Co0.2O2-Graphite Full Cell Cycling. J. Electrochem. Soc. 2017, 164 (7), A1579-A1586.

(27) Lee, D. J.; Im, D.; Ryu, Y.-G.; Lee, S.; Yoon, J.; Lee, J.; Choi, W.; Jung, I.; Lee, S.; Doo, S.-G. Phosphorus derivatives as electrolyte additives for lithium-ion battery: The removal of $\mathrm{O} 2$ generated from lithium-rich layered oxide cathode. J. Power Sources 2013, 243, 831835.

(28) Yim, T.; Han, Y. K. Tris(trimethylsilyl) Phosphite as an Efficient Electrolyte Additive To Improve the Surface Stability of Graphite Anodes. ACS Appl. Mater. Interfaces 2017, 9 (38), 3285132858 .

(29) Streich, D.; Erk, C.; Guéguen, A.; Müller, P.; Chesneau, F.-F.; Berg, E. J. Operando Monitoring of Early Ni-mediated Surface Reconstruction in Layered Lithiated Ni-Co-Mn Oxides. J. Phys. Chem. C 2017, 121 (25), 13481-13486.

(30) Guéguen, A.; Streich, D.; He, M.; Mendez, M.; Chesneau, F. F.; Novák, P.; Berg, E. J. Decomposition of LiPF6 in High Energy Lithium-Ion Batteries Studied with Online Electrochemical Mass Spectrometry. J. Electrochem. Soc. 2016, 163 (6), A1095-A1100.

(31) Streich, D.; Guéguen, A.; Mendez, M.; Chesneau, F.; Novák, P.; Berg, E. J. Online Electrochemical Mass Spectrometry of High Energy Lithium Nickel Cobalt Manganese Oxide/Graphite Half- and FullCells with Ethylene Carbonate and Fluoroethylene Carbonate Based Electrolytes. J. Electrochem. Soc. 2016, 163 (6), A964-A970.

(32) Bolli, C.; Guéguen, A.; Mendez, M. A.; Berg, E. J. Operando monitoring of F- formation in lithium ion batteries. Chem. Mater. 2019, 31, 1258-1267.

(33) He, M.; Boulet-Roblin, L.; Borel, P.; Tessier, C.; Novák, P.; Villevieille, C.; Berg, E. J. Effects of Solvent, Lithium Salt, and Temperature on Stability of Carbonate-Based Electrolytes for $5.0 \mathrm{~V}$ LiNi0.5Mn1.5O4 Electrodes. J. Electrochem. Soc. 2016, 163 (2), A83A89.

(34) $\mathrm{He}, \mathrm{M}$. Elucidating Interface Reactions in Li-Ion Batteries and Supercapacitors by In Situ Gas Analysis. Ph.D. Thesis, ETH Zürich, 2016.

(35) Solchenbach, S.; Metzger, M.; Egawa, M.; Beyer, H.; Gasteiger, H. A. Quantification of PF5 and POF3 from Side Reactions of LiPF6 in Li-Ion Batteries. J. Electrochem. Soc. 2018, 165, A3022-A3028.

(36) Qi, X.; Tao, L.; Hahn, H.; Schultz, C.; Gallus, D. R.; Cao, X.; Nowak, S.; Röser, S.; Li, J.; Cekic-Laskovic, I.; Rad, B. R.; Winter, M. Lifetime limit of tris(trimethylsilyl) phosphite as electrolyte additive for high voltage lithium ion batteries. RSC Adv. 2016, 6 (44), 3834238349 .

(37) Strehle, B.; Kleiner, K.; Jung, R.; Chesneau, F.; Mendez, M.; Gasteiger, H. A.; Piana, M. The Role of Oxygen Release from Li- and Mn-Rich Layered Oxides during the First Cycles Investigated by OnLine Electrochemical Mass Spectrometry. J. Electrochem. Soc. 2017, 164 (2), A400-A406.

(38) Heider, U.; Oesten, R.; Jungnitz, M. Challenge in manufacturing electrolyte solutions for lithium and lithium ion batteries quality control and minimizing contamination level. J. Power Sources 1999, 81-82, 119-122.

(39) Michan, A. L.; Parimalam, B. S.; Leskes, M.; Kerber, R. N.; Yoon, T.; Grey, C. P.; Lucht, B. L. Fluoroethylene Carbonate and Vinylene Carbonate Reduction: Understanding Lithium-Ion Battery Electrolyte Additives and Solid Electrolyte Interphase Formation. Chem. Mater. 2016, 28 (22), 8149-8159.
(40) Jung, R.; Metzger, M.; Haering, D.; Solchenbach, S.; Marino, C.; Tsiouvaras, N.; Stinner, C.; Gasteiger, H. A. Consumption of Fluoroethylene Carbonate (FEC) on Si-C Composite Electrodes for Li-Ion Batteries. J. Electrochem. Soc. 2016, 163 (8), A1705-A1716.

(41) Freiberg, A. T. S.; Roos, M. K.; Wandt, J.; de Vivie-Riedle, R.; Gasteiger, H. A. Singlet Oxygen Reactivity with Carbonate Solvents Used for Li-Ion Battery Electrolytes. J. Phys. Chem. A 2018, 122 (45), $8828-8839$.

(42) Renfrew, S. E.; McCloskey, B. D. Residual Lithium Carbonate Predominantly Accounts for First Cycle $\mathrm{CO} 2$ and $\mathrm{CO}$ Outgassing of Li-Stoichiometric and Li-Rich Layered Transition-Metal Oxides. J. Am. Chem. Soc. 2017, 139 (49), 17853-17860.

(43) Buqa, H.; Würsig, A.; Vetter, J.; Spahr, M. E.; Krumeich, F.; Novák, P. SEI film formation on highly crystalline graphitic materials in lithium-ion batteries. J. Power Sources 2006, 153 (2), 385-390.

(44) Imhof, R.; Novák, P. In Situ Investigation of the Electrochemical Reduction of Carbonate Electrolyte Solutions at Graphite Electrodes. J. Electrochem. Soc. 1998, 145 (4), 1081-1087.

(45) Bernhard, R.; Metzger, M.; Gasteiger, H. A. Gas Evolution at Graphite Anodes Depending on Electrolyte Water Content and SEI Quality Studied by On-Line Electrochemical Mass Spectrometry. J. Electrochem. Soc. 2015, 162 (10), A1984-A1989.

(46) Borodin, O.; Olguin, M.; Ganesh, P.; Kent, P. R.; Allen, J. L.; Henderson, W. A. Competitive lithium solvation of linear and cyclic carbonates from quantum chemistry. Phys. Chem. Chem. Phys. 2016, 18 (1), 164-75.

(47) Hou, T.; Yang, G.; Rajput, N. N.; Self, J.; Park, S.-W.; Nanda, J.; Persson, K. A. The influence of FEC on the solvation structure and reduction reaction of LiPF6/EC electrolytes and its implication for solid electrolyte interphase formation. Nano Energy 2019, 64, 103881.

(48) Ravikumar, B.; Mynam, M.; Rai, B. Effect of Salt Concentration on Properties of Lithium Ion Battery Electrolytes: A Molecular Dynamics Study. J. Phys. Chem. C 2018, 122 (15), 8173-8181.

(49) Bogle, X.; Vazquez, R.; Greenbaum, S.; Cresce, A.; Xu, K. Understanding $\mathrm{Li}(+)$-Solvent Interaction in Nonaqueous Carbonate Electrolytes with (17)O NMR. J. Phys. Chem. Lett. 2013, 4 (10), 1664-8.

(50) Giorgini, M. G.; Futamatagawa, K.; Torii, H.; Musso, M.; Cerini, S. Solvation Structure around the Li+ Ion in Mixed Cyclic/ Linear Carbonate Solutions Unveiled by the Raman Noncoincidence Effect. J. Phys. Chem. Lett. 2015, 6 (16), 3296-3302.

(51) Metzger, M.; Strehle, B.; Solchenbach, S.; Gasteiger, H. A. Hydrolysis of Ethylene Carbonate with Water and Hydroxide under Battery Operating Conditions. J. Electrochem. Soc. 2016, 163 (7), A1219-A1225.

(52) Westheimer, F. H.; Huang, S.; Covitz, F. Rates and mechanisms of hydrolysis of esters of phosphorous acid. J. Am. Chem. Soc. 1988, 110 (1), 181-185.

(53) Plakhotnyk, A. V.; Ernst, L.; Schmutzler, R. Hydrolysis in the system LiPF6-propylene carbonate-dimethyl carbonate- H2O. J. Fluorine Chem. 2005, 126 (1), 27-31.

(54) Kim, K.; Park, I.; Ha, S.-Y.; Kim, Y.; Woo, M.-H.; Jeong, M.-H.; Shin, W. C.; Ue, M.; Hong, S. Y.; Choi, N.-S. Understanding the thermal instability of fluoroethylene carbonate in LiPF6-based electrolytes for lithium ion batteries. Electrochim. Acta 2017, 225, $358-368$.

(55) Xu, C.; Hernández, G.; Abbrent, S.; Kobera, L.; Konefal, R.; Brus, J.; Edström, K.; Brandell, D.; Mindemark, J. Unraveling and Mitigating the Storage Instability of Fluoroethylene CarbonateContaining LiPF6 Electrolytes To Stabilize Lithium Metal Anodes for High-Temperature Rechargeable Batteries. ACS Applied Energy Materials 2019, 2 (7), 4925-4935. 